\title{
Immunohistochemical Evaluation of 5- hydroxymethylcytosine (5-hmC) in Breast Phyllodes Tumors
}

\author{
Jasmine Vickery \\ University of Chicago 1
}

\section{Lisa Han}

University of Chicago 1

\section{Stephen Dzul}

Wayne State University 2

\section{Wei Zhang}

Northwestern University 3

\section{Zhou Zhang}

Northwestern University 3

\section{Razvan Lapadat}

North Shore

\section{Husain Sattar}

University of Chicago 1

Jeffrey Mueller

University of Chicago 1

\section{Thomas Krausz}

University of Chicago 1

Anna Biernacka ( $\square$ abiernacka@bsd.uchicago.edu )

University of Chicago 1

\section{Short Report}

Keywords: breast, phyllodes tumor, 5-hydroxymethylcytosine, 5-hmC, immunohistochemistry, fibroepithelial lesion, fibroadenoma, methylation, epigenetic

Posted Date: February 23rd, 2022

DOI: https://doi.org/10.21203/rs.3.rs-1374884/v1

License: (9) (7) This work is licensed under a Creative Commons Attribution 4.0 International License. Read Full License 


\section{Abstract}

Phyllodes tumors (PTs) pose a significant diagnostic challenge in breast pathology as histological criteria and cutoffs for grading are complex and arbitrary. Nevertheless, the clinical behavior of PTs varies widely and correlates, in part, with the histological grade. Methylation signatures have gained interest as diagnostic and prognostic tools in a variety of neoplasms. In particular, 5-hydroxymethylcytosine (5-hmC) has been found to be a useful biomarker. Herein, we assess 51 PTs of varying grades and 15 cellular fibroadenomas (cFA) for stromal expression of 5-hmC by immunohistochemistry. We demonstrate that nuclear 5-hmC decreases as PT grade increases, correlating with histologic predictors of adverse behavior, while it shows comparable levels in benign PTs and cFAs. We identify thresholds at which reduced 5-hmC levels help to distinguish borderline and malignant PT from their benign counterparts. Our results indicate that 5 -hmC may serve as a valuable adjunct in classifying PTs in diagnostically difficult cases.

\section{Introduction}

Phyllodes tumors (PTs) are a heterogeneous group of fibroepithelial lesions of the breast. They are graded based on multiple morphologic criteria and classified as benign, borderline, or malignant (1). The features incorporated in the grading scheme include tumor borders, stromal cellularity, atypia, mitotic activity, and presence or absence of stromal overgrowth or malignant heterologous elements. These tumor characteristics are evaluated in combination; however, it is not uncommon for a PT to exhibit features from more than one category. Some parameters such as stromal cellularity or cytologic atypia are subjective. Furthermore, there may be marked intralesional heterogeneity and prioritization of certain criteria by a pathologist, e.g., brisk mitotic activity ( $\geq 10$ mitotic figures per 10 high power fields) prompting classification as higher grade (2). To further add to the confusion, benign PTs show overlapping features with another fibroepithelial lesion, cellular fibroadenoma (cFA). Nevertheless, the accurate categorization of PTs is clinically important. The risk of local recurrence increases with histologic grade with overall recurrence rates in the literature of $10-17 \%, 14-25 \%$, and 23-30\% for benign, borderline, and malignant PTs, respectively (2). Whereas distant metastases have not been reported in benign PTs and are only rarely seen in borderline PTs (<1\%), malignant PTs spread hematogenously to other organs in up to $22 \%$ of cases. Most patients with metastatic malignant PT behave aggressively and have a dismal outcome $(2,3)$.

Reversible epigenetic methylation of genomic DNA is essential for the regulation of gene expression. Suppression proceeds through methylation of DNA base cytosine forming 5-methylcytosine (5-mC), while increased gene expression follows demethylation, converting 5-mC to 5-hydroxymethylcytosine (5-hmC). Diverse human malignancies are characterized by altered methylation pathways, one of which involves the reduced conversion of 5-mC to 5 -hmC and a consequent decrease in nuclear 5-hmC (4). Invariably reduced levels of 5-hmC have been reported in tumors of the lung, colon, brain, breast, liver, prostate, kidney, etc., compared to its respective normal tissues (5). Reduction in nuclear 5-hmC is reportedly detectable by immunohistochemistry (IHC) (6). Nuclear loss of 5-hmC staining has proven useful in determining benign from malignant lesions in melanoma, mesothelioma, breast carcinoma, among others $(6,7,8)$. Previous studies have shown different methylation patterns in borderline and malignant PTs compared to benign PTs and fibroadenomas $(9,10)$. However, to date, the utility of immunohistochemistry for methylation-related proteins such as 5 -hmC has not been established in fibroepithelial lesions. 
Considering the shortcomings of the current grading system, we hypothesized that 5-hmC IHC could assist in the classification and risk stratification on breast PTs. Herein, we examined 5-hmC levels in the stroma of PTs in relation to the clinicopathologic characteristics. Since cFA comes into a differential diagnosis of benign Phyllodes, it was also included in the study.

\section{Materials And Methods}

Following institutional review board approval, 66 representative cases of breast fibroepithelial lesions were selected. These included 30 benign, 11 borderline, and 10 malignant PTs and 15 cFA. From these cases, a formalin-fixed, paraffin-embedded representative tissue section was stained with hematoxylin and eosin (H\&E). All H\&E-stained slides were reviewed by five pathologists blinded to the diagnosis in order to confirm the original diagnosis and to document the criteria used to classify the fibroepithelial lesion.

The 5-hmC immunohistochemical stain was performed on the same tissue sections using a Leica Bond RX automatic stainer with a 15-min antigen retrieval (epitope retrieval solution I, Leica Biosystems, AR9961) and the 25-min UCH DAB-modified protocol with the primary anti-5-hmC antibody (1:1500; Active Motif, Inc., Carlsbad, CA). Antigen-antibody binding was detected with Bond polymer refine detection (Leica Biosystems, DS9800).

The intensity and percent positivity of lesional stromal cell nuclei were assessed by the same five pathologists. 5 -hmC staining of benign breast stromal, epithelial cells, and lymphocytes present on the same slide served as an internal control. A final score was calculated by multiplying the intensity ( $1=$ weak, $2=$ moderate, $3=$ strong) and proportion ( $1=0-25 \%, 2=26-50 \%, 3=51-75 \%, 4=76-100 \%)$ of 5 -hmC staining in tumor nuclei as compared to internal controls, with a minimum score of 1 and a maximal score of 12. Linear regression, Fisher's exact test, and ROC curve were used for statistical analysis (Microsoft Inc, Redmond, CA).

\section{Results}

The mean quantitated expression of 5 -hmC showed a significant gradual reduction as PT grade increased ( $p<0.001$, Table 1, Figure 1). Mean quantitated 5-hmC loss was significantly greater in malignant PT (mean 5$\mathrm{hmC}$ score 2.3 \pm SD 2.1) as compared to borderline (mean 5-hmC score 6.3 \pm SD 3.5) and benign (mean 5-hmC score 11.4 \pm SD 1.6) tumors ( $p=0.001$ ). However, 5-hmC expression did not differ significantly between cFA

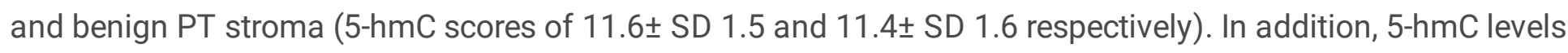
significantly decreased with the presence of many adverse histologic features. 5-hmC staining showed a statistically significant decrease in lesions with larger tumor size, infiltrative margin, marked stromal cellularity, marked stromal cell atypia, increased stromal mitoses, as well as the presence of stromal overgrowth and malignant heterologous elements $(p<0.001)$. Other qualities of the lesions, such as prominent leaf-like fronds and heterogeneity in stromal cell distribution also showed association with 5-hmc levels, although less significant $(p<0.05)$. Predominant tumor architecture (pericanalicular, intracanalicular, or mixed) and heterogeneous gland-to-stroma ratio were not associated with the mean 5-hmC score. Defining borderline PT by an IHC score of $\leq 95$-hmC showed a sensitivity of $90.5 \%$ and specificity of $91.1 \%$. For malignant PT defined as score $\leq 3,5-\mathrm{hmC}$ IHC achieved a sensitivity of $90 \%$ and specificity of $96.4 \%$. 
Table 1

5hmC expression and tumor characteristics

\begin{tabular}{|c|c|c|c|c|c|c|c|}
\hline \multirow{2}{*}{\multicolumn{2}{|c|}{ Parameters }} & \multirow{2}{*}{$\begin{array}{l}\text { Cellular } \\
\mathrm{FA} \text {, } \\
\mathrm{N}=15\end{array}$} & \multicolumn{3}{|c|}{ Phyllodes tumors, $\mathrm{N}=51$} & \multirow{2}{*}{$\begin{array}{l}5 \mathrm{hmc} \\
\text { (mean } \pm \\
\text { SD) }\end{array}$} & \multirow{2}{*}{$\begin{array}{l}\mathrm{p}- \\
\text { value }\end{array}$} \\
\hline & & & $\begin{array}{l}\text { Benign, } \\
N=30 \\
(58.8 \%)\end{array}$ & $\begin{array}{l}\text { Borderline, } \\
\mathrm{N}=11 \\
(21.6 \%)\end{array}$ & $\begin{array}{l}\text { Malignant, } \\
\mathrm{N}=10 \\
(19.6 \%)\end{array}$ & & \\
\hline \multicolumn{2}{|c|}{ Tumor size $(\mathrm{cm}$, mean $\pm \mathrm{SD})$} & $2.4 \pm 1.3$ & $2.7 \pm 1.7$ & $4.8 \pm 3.0$ & $9.5 \pm 8.5$ & $9.2 \pm 4.0$ & 0.001 \\
\hline \multicolumn{2}{|c|}{$5 \mathrm{hmC}$ IHC score (mean \pm SD) } & $11.6 \pm 1.5$ & $11.4 \pm 1.6$ & $6.3 \pm 3.5$ & $2.3 \pm 2.1$ & & \\
\hline \multirow{2}{*}{$\begin{array}{l}\text { Tumor } \\
\text { margin }\end{array}$} & Circumbscribed & 15 & 29 & 5 & 1 & $10.7 \pm 2.9$ & \multirow[t]{2}{*}{$<0.001$} \\
\hline & Infiltrative & & 1 (focal) & 6 (focal) & 9 & $4.7 \pm 3.9$ & \\
\hline \multirow[t]{3}{*}{ Architecture } & Intracanalicular & 3 & 17 & 7 & 7 & $8.6 \pm 4.3$ & \multirow[t]{3}{*}{0.367} \\
\hline & Pericanalicular & 10 & 6 & 2 & 1 & $10.2 \pm 3.2$ & \\
\hline & Mixed & 2 & 7 & 2 & 2 & $9.4 \pm 4.7$ & \\
\hline \multirow{2}{*}{$\begin{array}{l}\text { Prominent } \\
\text { leaf-like } \\
\text { fronds }\end{array}$} & Absent & 15 & 15 & 5 & 4 & $10.1 \pm 3.6$ & \multirow[t]{2}{*}{0.043} \\
\hline & Present & & 15 & 6 & 6 & $8.0 \pm 4.4$ & \\
\hline \multirow{2}{*}{$\begin{array}{l}\text { Gland-to- } \\
\text { stroma ratio }\end{array}$} & Uniform & 13 & 8 & 3 & 1 & $10.3 \pm 3.3$ & \multirow[t]{2}{*}{0.083} \\
\hline & Variable & 2 & 22 & 8 & 9 & $8.5 \pm 4.4$ & \\
\hline \multirow{3}{*}{$\begin{array}{l}\text { Stromal } \\
\text { cellularity }\end{array}$} & Mild & 5 & 21 & 1 & & $11.5 \pm 1.5$ & \multirow[t]{3}{*}{$<0.001$} \\
\hline & Moderate & 10 & 9 & 10 & 1 & $9.2 \pm 3.7$ & \\
\hline & Marked & & & & 9 & $2.3 \pm 2.2$ & \\
\hline \multirow{2}{*}{$\begin{array}{l}\text { Stromal cell } \\
\text { distribution }\end{array}$} & Uniform & 11 & 6 & & 1 & $10.9 \pm 2.8$ & \multirow[t]{2}{*}{0.039} \\
\hline & Variable & 4 & 24 & 11 & 9 & $8.6 \pm 4.3$ & \\
\hline \multirow{3}{*}{$\begin{array}{l}\text { Stromal cell } \\
\text { atypia }\end{array}$} & No/Mild & 14 & 26 & 1 & & $11.4 \pm 1.8$ & \multirow[t]{3}{*}{$<0.001$} \\
\hline & Moderate & 1 & 4 & 10 & 1 & $7.4 \pm 3.8$ & \\
\hline & Marked & & & & 9 & $2.3 \pm 2.2$ & \\
\hline \multirow{3}{*}{$\begin{array}{l}\text { Stromal } \\
\text { mitosis/10 } \\
\text { HPFs }\end{array}$} & 0 to 4 & 13 & 29 & 3 & & $11.0 \pm 2.4$ & \multirow[t]{3}{*}{$<0.001$} \\
\hline & 5 to 9 & 1 & 1 & 5 & 1 & $7.8 \pm 4.2$ & \\
\hline & $\geq 10$ & 1 & & 3 & 9 & $3.7 \pm 3.4$ & \\
\hline \multirow{2}{*}{$\begin{array}{l}\text { Stromal } \\
\text { overgrowth }\end{array}$} & Absent & 15 & 30 & 7 & 4 & $10.0 \pm 3.5$ & \multirow[t]{2}{*}{$<0.001$} \\
\hline & Present & & & 4 (focal) & 6 & $5.0 \pm 4.5$ & \\
\hline \multirow{2}{*}{$\begin{array}{l}\text { Heterologous } \\
\text { elements }\end{array}$} & Absent & 15 & 30 & 11 & 6 & $9.7 \pm 3.6$ & \multirow[t]{2}{*}{0.006} \\
\hline & Present & & & & 4 & $1.3 \pm 0.5$ & \\
\hline
\end{tabular}




\section{Discussion}

Phyllodes tumors show a broad spectrum of clinical behavior. Careful morphological evaluation remains the mainstay of diagnosis and classification of these tumors; however, histological criteria and cutoffs for grading are complex and quite arbitrary. A number of immunohistochemical markers, including Ki-67, p53, CD117 (ckit), vascular endothelial growth factor (VEGF), and epidermal growth factor receptor (EGFR), have been proposed to assist in the workup of PTs, with variable sensitivity, specificity, and uptake into routine pathology practice. (11)

Mounting evidence exists that the pathway to cancer leads through a gradual accumulation of interacting epigenetic and genetic events over time. Most studies to date have concentrated on the genetic alterations in PTs, e.g., chromosomal imbalances $(12,13)$ or somatic mutations (e.g., MED12 and TERT genes) $(14,15)$. Few investigators have evaluated PT methylation status. Huang et al. showed significantly elevated methylation of RASSF1A and TWIST1 promoters in PTs compared with fibroadenomas (9). Kim et al. demonstrated a trend in increasing methylation frequency of five genes (GSTP1, HIN-1, RAR-beta, RASSF1A, and TWIST1) according to the histologic grade of PTs (10). The same authors reported that methylation profiles segregate PTs into two distinct groups: the benign and the combined borderline/malignant. These studies have brought attention to epigenetic mechanisms as possible diagnostic and/or prognostic tools in PTs.

Here we report that IHC expression of an epigenetic marker 5-hmC in the stroma of PTs is associated with the histologic grade. Our data provide both a statistically significant and diagnostically relevant difference in the extent of 5-hmC loss between benign, borderline and malignant Phyllodes. Interestingly, benign PT and cFA show comparably high levels of $5-\mathrm{hmC}$. These data support previous studies on similarities between the two neoplasms (2).

We observe a strong correlation of 5-hmC levels with morphologic predictors of adverse behavior, including larger tumor size, infiltrative margin, marked stromal cellularity, marked stromal cell atypia, increased stromal mitoses, presence of stromal overgrowth, and presence of malignant heterologous elements. Other qualities of the lesions that we routinely evaluate, like prominent leaf-like fronds and heterogeneity in stromal cell distribution, are also associated with 5-hmC levels. Predominant tumor architecture or heterogeneous gland-tostroma ratio are not correlated with 5-hmC expression. At specific thresholds of IHC score, the reduced 5-hmC expression performs as a sensitive and specific marker for borderline and malignant PT, which is the most clinically important distinction.

In summary, our pilot study shows a promising role for 5-hmC immunohistochemistry in the diagnostic workup of challenging cases. Additional studies on larger cohorts are needed to validate the findings and to reproduce our data obtained in resection specimens in small biopsy samples. Finally, work examining additional 5-hmCrelated epigenetic and metabolic markers (including 5-mC, ten-eleven translocation enzymes, isocitrate dehydrogenase, succinate dehydrogenase, or fumarate dehydrogenase) may further elucidate the interplay of genetic and epigenetic alterations in pathogenesis.

\section{Abbreviations}


Phyllodes tumor (PT), 5-hydroxymethylcytosine (5-hmC), 5-methylcytosine (5-mC), cellular fibroadenomas (cFA), immunohistochemistry (IHC), vascular endothelial growth factor (VEGF), and epidermal growth factor receptor (EGFR), hematoxylin and eosin (H\&E)

\section{Declarations}

Ethics approval and consent to participate: This study is approved by the University of Chicago Institutional review board. Waiver of Consent Process and Consent Documentation as well as a waiver of HIPAA authorization were obtained. The University Federalwide Assurance number is FWA00005565. Current expiration date of the FWA is 3/14/2022. The University of Chicago IORG number is IORG0000201.

Consent for publication: The Authors hereby consent to publication of the Work in The Journal of Diagnostic Pathology.

Availability of data and materials: The datasets generated during and/or analysed during the current study are available from the corresponding author on reasonable request.

Competing interests: The authors declare that they have no competing interests

Funding: The study was supported internally by the Department of Pathology at the University of Chicago Medical Center.

Authors' contributions: AB, PD, and TK conceived and designed the project. AB, JV, and LH performed a selection of study cases and reviewed clinicopathologic parameters. AB, LH, JV, JM, and HS reviewed H\&E sections, confirmed diagnoses, and analyzed and quantified 5-hmC immunohistochemical staining. SD, RL, ZZ, and WZ performed statistical analysis of the data. AB, PD, and TK conceived and designed the project. AB, JV, and LH performed a selection of study cases and reviewed clinicopathologic parameters. AB, LH, JV, JM, and $\mathrm{HS}$ reviewed H\&E sections, confirmed diagnoses, and analyzed and quantified 5-hmC immunohistochemical staining. SD, RL, ZZ, and WZ performed statistical analysis of the data.

Acknowledgements: We thank Dr. Terri Lee and the Human Tissue Resource Center for performing immunohistochemical staining. We thank Ryan McGary and the Histology Section for the preparation of tissue sections.

\section{References}

1. Tan, P H, Ellis, I, Allison, K, Brogi, E, Fox, S B, Lakhani, S, Lazar, A J, Morris, E A, Sahin, A, Salgado, R, Sapino, A, Sasano, H, Schnitt, S, Sotiriou, C, van Diest, P, White, V A, Lokuhetty, D, Cree, I A \& for the WHO Classification of Tumours Editorial Board. (2020) Histopathology 77, 181- 185.

https://doi.org/10.1111/his.14091 The 2019 World Health Organization classification of tumours of the breast

2. Tan BY, Acs G, Apple SK, Badve S, Bleiweiss IJ, Brogi E, Calvo JP, Dabbs DJ, Ellis IO, Eusebi V, Farshid G, Fox SB, Ichihara S, Lakhani SR, Rakha EA, Reis-Filho JS, Richardson AL, Sahin A, Schmitt FC, Schnitt SJ, Siziopikou KP, Soares FA, Tse GM, Vincent-Salomon A, Tan PH. Phyllodes tumours of the breast: a 
consensus review. Histopathology. 2016 Jan,68(1):5-21. doi: 10.1111/his.12876. PMID: 26768026, PMCID: PMC5027876.

3. Krings G, Bean GR, Chen YY. Fibroepithelial lesions, The WHO spectrum. Semin Diagn Pathol. 2017 Sep,34(5):438-452. doi: 10.1053/j.semdp.2017.05.006. Epub 2017 May 28. PMID: 28688536.

4. Vasanthakumar A, Godley LA. 5-hydroxymethylcytosine in cancer: significance in diagnosis and therapy. Cancer Genet. 2015 May,208(5):167-77. doi: 10.1016/j.cancergen.2015.02.009. Epub 2015 Mar 3. Erratum in: Cancer Genet. 2016 Apr,209(4):177. PMID: 25892122.

5. Mariani CJ, Madzo J, Moen EL, Yesilkanal A, Godley LA. Alterations of 5-hydroxymethylcytosine in human cancers. Cancers (Basel). 2013 Jun 25,5(3):786-814. doi: 10.3390/cancers5030786. PMID: 24202321, PMCID: PMC3795365.

6. Chapel DB, Husain AN, Krausz T. Immunohistochemical evaluation of nuclear 5-hydroxymethylcytosine (5$\mathrm{hmC}$ ) accurately distinguishes malignant pleural mesothelioma from benign mesothelial proliferations. Mod Pathol. 2019 Mar,32(3):376-386. doi: 10.1038/s41379-018-0159-7. Epub 2018 Oct 12. PMID: 30315275.

7. Lian CG, Xu Y, Ceol C, Wu F, Larson A, Dresser K, Xu W, Tan L, Hu Y, Zhan Q, Lee CW, Hu D, Lian BQ, Kleffel S, Yang Y, Neiswender J, Khorasani AJ, Fang R, Lezcano C, Duncan LM, Scolyer RA, Thompson JF, Kakavand H, Houvras Y, Zon LI, Mihm MC Jr, Kaiser UB, Schatton T, Woda BA, Murphy GF, Shi YG. Loss of 5-hydroxymethylcytosine is an epigenetic hallmark of melanoma. Cell. 2012 Sep 14,150(6):1135-46. doi: 10.1016/j.cell.2012.07.033. PMID: 22980977, PMCID: PMC3770275.

8. Tsai KW, Li GC, Chen CH, Yeh MH, Huang JS, Tseng HH, Fu TY, Liou HH, Pan HW, Huang SF, Chen CC, Chang HY, Ger LP, Chang HT. Reduction of global 5-hydroxymethylcytosine is a poor prognostic factor in breast cancer patients, especially for an ER/PR-negative subtype. Breast Cancer Res Treat. 2015 Aug,153(1):219-34. doi: 10.1007/s10549-015-3525-x. Epub 2015 Aug 8. PMID: 26253945.

9. Huang KT, Dobrovic A, Yan M, Karim RZ, Lee CS, Lakhani SR, Fox SB. DNA methylation profiling of phyllodes and fibroadenoma tumours of the breast. Breast Cancer Res Treat. 2010 Nov,124(2):555-65. doi: 10.1007/s10549-010-0970-4. Epub 2010 Jun 19. PMID: 20563638.

10. Kim JH, Choi YD, Lee JS, Lee JH, Nam JH, Choi C, Park MH, Yoon JH. Borderline and malignant phyllodes tumors display similar promoter methylation profiles. Virchows Arch. 2009 Dec,455(6):469-75. doi: 10.1007/s00428-009-0858-z. Epub 2009 Nov 19. PMID: 19924440.

11. Schnitt, S. J., \& Collins, L. C. (2013). Biopsy interpretation of the breast. Philadelphia: Wolters Kluwer Health/Lippincott Williams \& Wilkins.

12. Laé M, Vincent-Salomon A, Savignoni A, Huon I, Fréneaux P, Sigal-Zafrani B, Aurias A, Sastre-Garau X, Couturier J. Phyllodes tumors of the breast segregate in two groups according to genetic criteria. Mod Pathol. 2007 Apr,20(4):435-44. doi: 10.1038/modpathol.3800756. Epub 2007 Mar 2. PMID: 17334353.

13. Lv S, Niu Y, Wei L, Liu Q, Wang X, Chen Y. Chromosomal aberrations and genetic relations in benign, borderline and malignant phyllodes tumors of the breast: a comparative genomic hybridization study. Breast Cancer Res Treat. 2008 Dec,112(3):411-8. doi: 10.1007/s10549-007-9876-1. Epub 2008 Jan 13. PMID: 18189161.

14. Ng CC, Tan J, Ong CK, Lim WK, Rajasegaran V, Nasir ND, Lim JC, Thike AA, Salahuddin SA, Iqbal J, Busmanis I, Chong AP, Teh BT, Tan PH. MED12 is frequently mutated in breast phyllodes tumours: a study 
of 112 cases. J Clin Pathol. 2015 Sep,68(9):685-91. doi: 10.1136/jclinpath-2015-202896. Epub 2015 May 27. PMID: 26018969.

15. Yoshida M, Ogawa R, Yoshida H, Maeshima A, Kanai Y, Kinoshita T, Hiraoka N, Sekine S. TERT promoter mutations are frequent and show association with MED12 mutations in phyllodes tumors of the breast. $\mathrm{Br}$ J Cancer. 2015 Oct 20,113(8):1244-8. doi: 10.1038/bjc.2015.326. Epub 2015 Sep 10. PMID: 26355235, PMCID: PMC4647876.

\section{Figures}
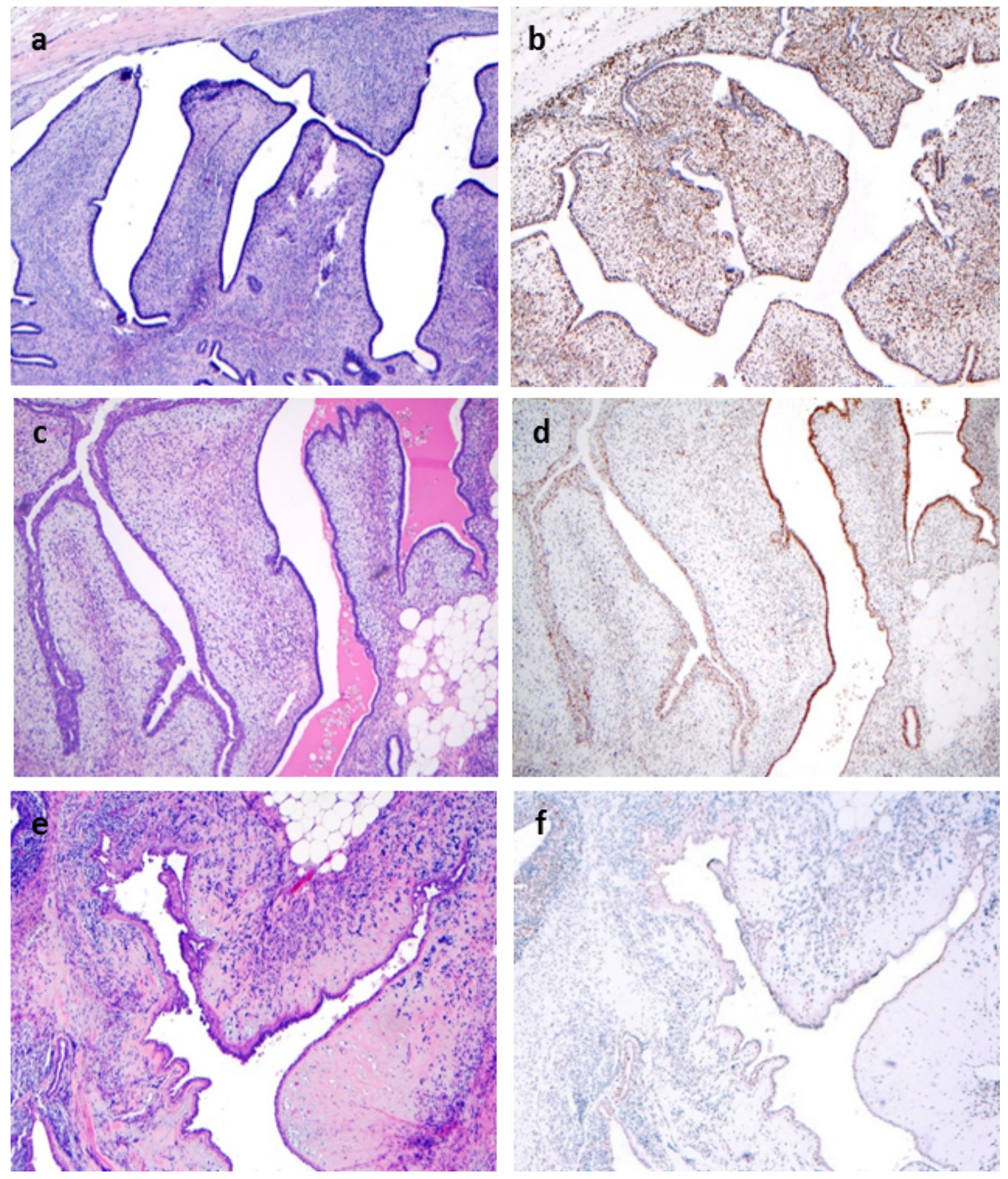

Figure 1 
Representative images of $\mathrm{H} \& \mathrm{E}$ and 5-hmC IHC in benign (A, B), borderline (C, D), and malignant (E, F) PTs (40x magnification). 